\title{
A produção acadêmica sobre avaliação da aprendizagem: Um olhar para estudos produzidos na área de Educação em Ciências
}

\author{
The academic production on learning assessment: A view at the studies produced in the field of
} Scientific Education

\author{
La producción académica sobre evaluación del aprendizaje: Una mirada a los estudios producidos \\ en el campo de la Educación Científica
}

Recebido: 11/06/2021 | Revisado: 19/06/2021 | Aceito: 22/06/2021 | Publicado: 04/07/2021

\author{
Kassiana da Silva Miguel \\ ORCID: https://orcid.org/0000-0003-0565-6343 \\ Universidade Estadual do Oeste do Paraná, Brasil \\ E-mail: kassianasmiguel@gmail.com \\ Alberto Lopo Montalvão Neto \\ ORCID: https://orcid.org/0000-0002-4875-646X \\ Universidade Estadual de Campinas, Brasil \\ E-mail: neto_19901812@yahoo.com.br \\ Daniela Frigo Ferraz \\ ORCID: https://orcid.org/0000-0002-2747-4818 \\ Universidade Estadual do Oeste do Paraná, Brasil \\ E-mail: dfrigoferraz@gmail.com \\ Lourdes Aparecida Della Justina \\ ORCID: https://orcid.org/0000-0001-6013-7234 \\ Universidade Estadual do Oeste do Paraná, Brasil \\ E-mail: lourdesjustina@gmail.com
}

\begin{abstract}
Resumo
A avaliação da aprendizagem é um campo complexo por envolver questões sociais, educacionais, políticas e relacionais, e a forma como ela vem sendo estudada e compreendida ao longo das décadas vem se modificando. Destarte, encontramos neste campo desde concepções mais tradicionais e objetivas (avaliação somativa), até concepções que aparentam ter um caráter mais qualitativo e processual, e que visam o (re)planejamento dos processos de ensino e de aprendizagem (avaliação diagnóstica e formativa). Com base nisso, temos como objetivo compreender a produção acadêmica sobre a "avaliação da aprendizagem". Para tal, consideramos os aportes teórico-conceituais adotados pelas pesquisas em Educação em Ciências. De natureza qualitativa, este artigo caracteriza-se como um estudo do tipo "estado da arte". Como instrumento de coleta de informações utilizamos um "Roteiro de Análise Textual" (RAT) e, a partir da construção de categorias, caracterizamos os trabalhos encontrados em um movimento descritivo-interpretativo. Foram encontrados nove artigos com foco de pesquisa no tema de interesse. Esse corpus de análise constituiu-se em meio a um universo de 768 artigos publicados no periódico "Ciência \& Educação" (1998 a 2017). Por meio da análise dessas pesquisas, nossos resultados apontam para a emergência de distintas concepções sobre a "avaliação da aprendizagem" nas pesquisas em Educação em Ciências. Ademais, apontamos que a maior parte desses estudos têm como ideia central a percepção de avaliação enquanto uma ação "integrante da prática educativa". Palavras-chave: Ensino; Avaliação da aprendizagem; Educação em ciências; Estado da arte; Prática educativa.
\end{abstract}

\begin{abstract}
Learning assessment is a complex field which involves social, educational, political, and related issues, and the way it has been studied and understood in recent decades has changed. In this field, they stand out, from more traditional and objective concepts (somatic evaluation) to concepts that seem to have a more qualitative and procedural character, which aim to (re)plan of teaching and learning processes (diagnostic and formative evaluation). Based on this, our objective is to understand the academic production about the "learning assessment". Therefore, we consider the theoretical-conceptual contributions of research in Science Education. Qualitative in nature, this article is characterized as a "state of the art" type study. As a tool for collecting information, we use a "Textual Analysis Roadmap" (RAT) and, based on the construction of categories, we characterize the works found in a descriptiveinterpretative movement. New articles were found as the focus of investigation, not a subject of interest. This corpus of constitutional analysis was issued for a universe of 768 articles published in the journal "Ciência \& Educação" (1998 to 2017). Through the analysis of research, our results are based on the emergence for different concepts about the "learning assessment" in research on Science Education. In addition, we point out that most studies have as their central idea to understand the assessment as an action "part of educational practice".
\end{abstract}


Keywords: Teaching; Learning assessment; Education in sciences; State of art; Educational practice.

\section{Resumen}

La evaluación del aprendizaje es un campo complejo porque involucra temas sociales, educativos, políticos y afines, y la forma en que se ha venido estudiando y comprendido en las últimas décadas, ha ido cambiando. En este campo se destacan, desde conceptos más tradicionales y objetivos (evaluación sumativa), hasta conceptos que parecen tener un carácter más cualitativo y procedimental, y que apuntan a (re)planificar los procesos de enseñanza y aprendizaje (diagnóstico y evaluación formativa). En base a esto, nuestro objetivo es comprender la producción académica sobre la "evaluación del aprendizaje". Por tanto, consideramos los aportes teórico-conceptuales adoptados por las investigaciones en Educación Científica. De naturaleza cualitativa, este artículo se caracteriza entonces, como un estudio de tipo "estado del arte". Como instrumento de recolección de información utilizamos un "Guión de Análisis Textual" por sus siglas en portugués (RAT: Roteiro de Análise Textual) y, a partir de la construcción de categorías, caracterizamos los trabajos encontrados en un movimiento descriptivo-interpretativo. Fueron encontrados nueve artículos con foco de investigación, en el tema de interés. Este corpus de análisis se constituyó en medio a un universo de 768 artículos publicados en la revista "Ciência \& Educação" (1998 a 2017). A través del análisis de la investigación, nuestros resultados apuntan en la emergencia de diferentes conceptos sobre la "evaluación del aprendizaje" en las investigaciones en Educación Científica. Además, apostamos a que la mayoría de los estudios tienen como idea central la percepción de evaluación en cuanto a una acción "integral de la práctica educativa".

Palabras clave: Ensenãnza; Evaluación del aprendizaje; Educación científica; Estado del arte; Práctica educativa.

\section{Introdução}

A avaliação educacional se coloca como objeto de pesquisas e estudos dos mais variados tipos e com enfoques diversos (Luckesi, 1996), isso porque, ela assume um papel central no trabalho do professor, em sua relação com o processo de ensino e aprendizagem. É por meio da avaliação que o professor identifica os progressos ou as dificuldades de seus alunos, sendo possível avaliá-los em diversos âmbitos ao longo do processo de construção do conhecimento.

A forma como a avaliação é compreendida e estudada ao longo das décadas vem se modificando, e por isso encontramos desde concepções mais tradicionais e objetivas (somativa), até aquelas que mostram um caráter diferenciado por pautarem-se em aspectos diagnósticos e formativos. Destarte, os exames escolares são colocados como um importante método de avaliação de conhecimentos em várias sociedades, datando de tempos longínquos, e encontram-se nos mesmos moldes há mais de meio século. Eles passam a ser uma efetiva preocupação no Brasil entre as décadas de 1960 e 1970, quando os documentos oficiais educacionais passam a falar não mais em exames escolares, mas em avaliação educacional (Luckesi, 1996). Nesse sentido, Luckesi (1996) coloca que examinar e avaliar possuem diferenças cruciais, pois, se examinar se caracteriza pela classificação e seletividade do educando, o ato de avaliar pretende diagnosticar e realizar a inclusão deste no processo de ensino-aprendizagem. $\mathrm{O}$ autor diz ainda que "o educando não vem para a escola para ser submetido a um processo seletivo, mas sim para aprender e, para tanto, necessita do investimento da escola e de seus educadores, tendo em vista efetivamente aprender". (Luckesi, 1996, p. 3).

Entendendo a avaliação como uma forma de diagnóstico da aprendizagem e considerando que ela está entre as práticas cotidianas escolares (Montalvão Neto \& Miguel, 2019) que mais influenciam as relações ensino-aprendizagem e professor-aluno, vemos que as discussões por especialistas da área apontam que esta não se resume apenas em uma etapa final do processo, nem mesmo se restringe a somatória de conhecimentos que resultam numa nota final, quantificando o conhecimento do aluno para fins de progressão escolar. Nesse viés, Barreira, Boavida e Araújo (2006) apontam três formas de avaliação: a) diagnóstica; b) formativa; c) somativa.

Como apontam Barreira, Boavida e Araújo (2006, p. 95), a avaliação formativa difere da somativa, pois "enquanto que esta é feita no final de um período de ensino para decidir a continuação de um determinado programa, a primeira é realizada processualmente, durante o decurso do programa, para introduzir ajustamentos no sentido do seu aperfeiçoamento". Outrossim, a "avaliação deixa de ser considerada numa perspectiva final e começa a ser encarada como uma avaliação formativa, processual, preocupando-se com as tomadas de decisão respeitantes ao processo de aprendizagem do aluno e ao 
processo de ensino do professor" (Barreira, Boavida \& Araújo, 2006, p. 96).

Partimos da concepção que uma análise sobre a produção do conhecimento sobre avaliação educacional, centrada em publicações científicas de periódicos reconhecidos pela comunidade acadêmica, se torna promissora, tendo em vista que esse campo ainda se encontra em vias de consolidação. Tal questão é reforçada por Borges (2011), que diz que a produção de conhecimento em "avaliação", proveniente de publicações científicas em periódicos, tem se constituído como um meio essencial no processo de construção de conhecimento sobre o tema. Assim, essa produção se apresenta como objeto de estudo de pesquisadores que buscam sistematizar e analisar o tema.

Destarte, neste estudo objetivamos compreender as principais concepções de "avaliação da aprendizagem" na pesquisa em Educação em Ciências, a partir da categorização e análise dos aportes teórico-conceituais de estudos publicados em um influente periódico da área. Para isso, assumimos pressupostos metodológicos do "estado da arte", "[...] por se tratar de um instrumento que busca a compreensão do conhecimento sobre determinado tema, em um período de tempo específico, e, consequentemente, sua sistematização e análise" (Teixeira, 2006, p. 60). Assim, mapeamos e organizamos os dados com base em buscas bibliográficas realizadas em um reconhecido periódico voltado à pesquisa em Ensino de Ciências: a revista "Ciência \& Educação".

\section{Avaliação da Aprendizagem: uma Abordagem Conceitual}

A avaliação é por natureza uma rede complexa, influenciada por contribuições teóricas da pedagogia, didática, psicologia, sociologia, antropologia e ética (Fernandes, 2009). Nesse sentido, de acordo com Liell, Bayer e Ledur (2018, p. 508):

O processo de avaliação, de modo geral, está associado à produção de informações sobre determinada realidade e constitui um elemento integrante do cotidiano escolar como forma de, tradicionalmente, aferir o aprendizado dos estudantes por meio de diferentes instrumentos (Liell, Bayer \& Ledur, 2018, p. 508).

Na década de 1930, Ralph Tyler designou pela primeira vez o termo "avaliação educacional". Nesse contexto, outros pesquisadores reconheceram a autoria de Tyler em estudos sobre avaliação, estabelecendo o período de 1930 a 1945 como "tyleriano" (Luckesi, 1996). O conceito de Tyler em relação à avaliação caracterizava-se por objetivos e com base na ideia de feedback, acreditando que por esse viés seria possível levar a prováveis melhorias no ensino. No entanto, essa ideia:

[...] ainda que inovadora para o período, era insuficiente por acreditar que a avaliação era um ato caracterizado como uma atividade final de alcance de objetivos, sem vinculá-la a um contínuo e sistemático processo em si, e para o qual também prevalecem julgamentos de valor (Depresbiteris, 1997, p. 8).

Destarte, Tyler entendia que o conceito de avaliação não poderia se restringir a uma ideia de julgamento. A partir de estudos mais apurados sobre o tema, entre 1930 e 1945, ele instituiu algumas mudanças em relação aos aspectos conceituais estabelecidos, indo da investigação da aprendizagem individual e/ou coletiva dos alunos para a preocupação com outros aspectos, tais como os objetivos envolvidos, a relação com o currículo e a relação com a prática de professores (Saul, 1994).

Além de Tyler, outros autores também se voltaram aos estudos sobre avaliação. Como exemplo podemos citar Michael Scriven, que, de acordo com Pinto e Rocha (2011), foi o primeiro a utilizar o termo "avaliação formativa" em 1967 (Scriven, 1967). Seus estudos relacionavam-se ao currículo e para Scriven (2007, p. 1), a avaliação formativa é um "processo de determinar mérito, valor ou significado; uma avaliação é produto desse processo". O autor ainda considera que a lógica geral da avaliação integra quatro passos fundamentais: 1) Estabelecer critérios de mérito; 2) Construir padrões de comparação; 3) Medir o desempenho e compará-lo com os padrões; e, 4) Integrar os dados num juízo sobre o mérito ou valor. 
A partir da década de 1980 marca-se, no Brasil, a influência de ideias norte-americanas. Segundo Borges (2011), as preocupações de pesquisadores com a avaliação emergem principalmente nessa década, marcada por uma menor dependência ao positivismo e reconhecimento da necessidade de incorporar novas teorias e modelos para minimizar os problemas do sistema educacional.

Considerando tais prerrogativas, entendemos que partir de um princípio de avaliação que considera vários aspectos do processo de ensino e aprendizagem, e que qualifica a aprendizagem sem impor juízos de valor, caracteriza-se como parte do processo avaliativo. Como apontam Barreira, Boavida e Araújo (2006), nessa perspectiva de avaliação formativa, considera-se que avaliar é algo processual e necessita de olhares outros que não voltados a resultados finalistas e objetivos.

Nessa perspectiva, outro autor que também expandiu o uso do termo avaliação formativa foi Benjamin Bloom, que, em conjunto com outros dois pesquisadores, Thomas Hastings e George Madaus, trabalharam sobre o termo no livro "Manual de Avaliação Formativa e Somativa do aprendizado escolar". Publicado em 1983, o livro resgata os conceitos de Scriven sobre avaliação. Ademais, na década de 1990 muitos outros pesquisadores destacam-se nos estudos sobre esse tipo de avaliação, estando entre eles Vianna (1989), Muramoto (1991), Hoffmann (1995), Luckesi (1996), Perrenoud (1999), Saul (2001), Hadji (2001) e Sanmartí (2009). Esses autores estão entre aqueles que trouxeram uma abordagem mais crítica em relação às discussões sobre avaliação.

Podemos dizer que uma das principais funções da avaliação formativa é contribuir para uma boa regulação da atividade de ensino, ou seja, trata-se de levantar informações úteis à regulação do processo de ensino-aprendizagem. Porém, compreendemos que "uma avaliação não precisa conformar-se a nenhum padrão metodológico para ser formativa" (Hadji, 2001, p. 19). Além disso, segundo Perrenoud (1999, p. 15), "a verdadeira avaliação formativa é necessariamente acompanhada de uma intervenção diferenciada, em termos de meios de ensino, de organização dos horários, de organização do grupo-aula, e de transformações radicais das estruturas escolares". Destarte, as mudanças imprescindíveis para qualificar a avaliação precisam estar integradas a todo sistema escolar.

Diante desses, podemos dizer que avaliar é estabelecer o valor de algo para uma dada finalidade, de forma que a avaliação da aprendizagem tem por objetivo coletar "informações para julgar o valor de um programa, produto, procedimento ou objetivo, ou ainda, a apreciar a utilidade potencial de abordagens alternativas para atingir determinados propósitos" (Vianna, 1989, p. 41). Todavia, Muramoto (1991) aponta que a avaliação não deve se restringir à dinâmica da sala de aula, devendo abranger muito mais do que isso.

É necessário, portanto, entender o julgamento das atividades e as relações desenvolvidas na escola, bem como a forma de organização do trabalho pedagógico e do projeto escolar. Outrossim, quando professores discutem em conjunto as decisões e a gestão escolar, tendem a criar um clima propício ao debate de ideias, o que leva à discussão coletiva e ao envolvimento de seus alunos nas decisões de sala de aula. Nessa perspectiva, é importante que o professor reflita sobre a importância da avaliação da aprendizagem, do conhecimento acerca das diversas práticas, dos instrumentos avaliativos e do desenvolvimento/construção do conhecimento de seus alunos.

Segundo Luckesi (1996), avaliar não se limita a um julgamento "definitivo" sobre alguma coisa, pessoa ou situação, mas diz respeito ao diagnóstico, a inclusão, tendo como objetivo a melhoria do ciclo de vida. Desse modo, por questões históricas, sociais e pessoais, temos dificuldades em compreendê-lo e praticá-lo. Por essas razões a avaliação se relaciona mais com sentimentos de penalidade, fracasso, rejeição, aviltamento (Luckesi, 1996), do que com sentimentos de averiguação, análise, compreensão, interação e autoanálise. Em outras palavras, não vemos a avaliação como um ato de superação daquilo que se apresenta como insuficiente no processo de ensino-aprendizagem.

Em consonância com o apresentado por Luckesi (1996), refletindo sobre a avaliação da aprendizagem no Ensino Superior, Machado et al. (2021) apontam que este é um relevante e complexo tema no âmbito do cenário educacional 
brasileiro. Para os autores, a avaliação "[...] não é um instrumento de controle, classificação ou coerção, mas um instrumento para investigar o nível de aprendizado dos acadêmicos". Destarte, o ato de avaliar não está dissociado "[...] do processo ensinoaprendizagem, haja vista que esta subsidia a informação ao docente, quanto ao desenvolvimento do acadêmico, bem como informações para este refletir e (re)pensar sua própria prática pedagógica” (Machado et al., 2021, p. 1). Ademais, os autores apontam que há uma baixa produção de pesquisas a respeito desta temática no âmbito do ensino superior.

Essas questões trazem reflexões sobre as questões o processo de avaliação e seus instrumentos avaliativos, que devem ser instituídos de forma reflexiva e gradual ao longo de todo o processo educacional. Nesse sentido, a prática avaliativa deve ser integradora do processo de ensino e aprendizagem, ou seja, da construção do conhecimento, pois "avaliar é dinamizar oportunidades de ação-reflexão, num acompanhamento permanente do professor, que incitará o aluno a novas questões" (Hoffmann, 1995, p.20). Conjuntamente ao processo avaliativo, numa perspectiva de ensino que se quer emancipatório, com aprendizagens críticas, consideramos que a avaliação se caracteriza como um processo de análise e crítica de uma dada realidade, visando a sua transformação (Saul, 2001).

Numa avaliação com enfoque libertador, tem-se o intuito de suscitar críticas e que os sujeitos escrevam a sua própria história, empoderando-se. Esse processo de avaliação está relacionado a uma concepção de aprendizagem que acredita que aprender também é superar obstáculos e erros, considerando que, como "as estratégias e os métodos de avaliação aplicados nos processos de ensino e aprendizagem têm uma extraordinária repercussão dos resultados desses processos, não é possível separar a avaliação dos processos de ensino e aprendizagem" (Sanmartí, 2009, p. 7).

Esses argumentos apontam para a importância de considerarmos os objetivos de avaliar, sendo necessário ressaltar que mesmo a avaliação formativa pode não atender ao propósito de construção crítica de aprendizagens. No entanto, a avaliação, quando objetiva a tomada de consciência do aluno em relação aos processos de aprendizagem, se caracteriza como um modelo formativo de avaliação. Isso porque, a todo o momento o aluno analisa as suas dificuldades sob a intervenção pedagógica, tendo o apoio do docente, que exerce o papel de mediador da aprendizagem.

Entendemos que no processo avaliativo torna-se fundamental a existência do diálogo, aproximação e mediação entre as ações do professor (ensino) e os caminhos de aprendizagem dos alunos. Destarte, considerando essa importância dos processos avaliativos nas concepções de ensino-aprendizagem, tomamos este tema como foco deste estudo, julgando como necessária a compreensão sobre "o que" e "como" se produzem pesquisas que pautadas nesse enfoque avaliativo.

\section{Metodologia}

De natureza qualitativa (Flick, 2009, Patton, 2001), esta pesquisa caracteriza-se como exploratória e bibliográfica (Gil, 2008, Minayo, Deslandes, Cruz Neto, \& Gomes, 1994, Lüdke \& André, 1986). A opção metodológica justifica-se em razão de que consideramos que o tema "avaliação da aprendizagem", apesar de ser largamente estudado em seus aspectos gerais, ainda é pouco pesquisado no âmbito do Ensino de Ciências. Essa observação é posta com base numa pesquisa maior, recentemente desenvolvida pela primeira autora deste trabalho, a nível de doutoramento ${ }^{1}$. Em sua tese, o tema em questão é investigado a partir de revisões de literatura em algumas das principais revistas de pesquisa em Ensino de Ciências. Algo similar foi observado por Reis et al. (2020), que, ao caracterizarem a produção acadêmica em Educação em Ciências e Educação Matemática, apontam para a escassez de pesquisas sobre o tema "avaliação". Assim, ao observarmos que se trata de um tema pouco explorado, enquadramos este estudo como exploratório, visto que:

\footnotetext{
${ }^{1}$ A referida tese foi recentemente defendida e aprovada, estando em vias de publicação.
} 
As pesquisas exploratórias têm como principal finalidade desenvolver, esclarecer e modificar conceitos e ideias, tendo em vista a formulação de problemas mais precisos ou hipóteses pesquisáveis para estudos posteriores. [...] Este tipo de pesquisa é realizado especialmente quando o tema escolhido é pouco explorado e torna-se difícil sobre ele formular hipóteses precisas e operacionalizáveis. [...] Muitas vezes as pesquisas exploratórias constituem a primeira etapa de uma investigação mais ampla (Gil, 2008, p. 27).

Consideramos ainda que este estudo se caracteriza como bibliográfico, pelo fato de que, além da pesquisa bibliográfica ser parte comum das pesquisas exploratórias, ela permite "[...] investigador a cobertura de uma gama de fenômenos muito mais ampla do que aquela que poderia pesquisar diretamente" (Gil, 2008, p. 50). Nesse sentido, buscando nessa investigação compreender as concepções sobre um tema tão amplo como a "Avaliação da Aprendizagem" no Ensino de Ciências, inspiramo-nos em pressupostos do "estado da arte".

No âmbito da presente pesquisa, consideramos que os estudos relativos ao estado da arte podem ser caracterizados como uma modalidade da pesquisa bibliográfica, e que, cada vez mais, esse tipo de estudo está ganhando espaço e notoriedade no âmbito das pesquisas acadêmica, tornando-se promissores por permitirem mapear e discutir determinada produção acadêmica em múltiplos campos do conhecimento (Fiorentini \& Lorenzato, 2006). Na sequência discorremos sobre alguns fundamentos desse tipo de pesquisa.

\section{Algumas Considerações Sobre o "Estado da Arte"}

Como dissemos, esta pesquisa inspira-se em estudos do tipo "estado da arte". Romanowski e Ens (2006, p. 39) apontam que esse tipo de estudo "[...] possibilita contribuir com a organização e análise na definição de um campo, uma área", em certo período de tempo, "além de indicar possíveis contribuições da pesquisa para com as rupturas sociais". Além disso, os autores apontam que "a análise do campo investigativo é fundamental neste tempo de intensas mudanças associadas aos avanços crescentes da ciência e tecnologia" (Romanowski \& Ens, 2006, p. 39).

De acordo com Ferreira (2002, p. 258), pesquisas do tipo "estado da arte" tem como foco "[...] mapear e discutir uma certa produção acadêmica em diferentes campos do conhecimento, tentando responder que aspectos e dimensões vêm sendo destacados e privilegiados em diferentes épocas e lugares, de que formas, e em que condições, têm sido produzidas". Ademais, para Romanowski e Ens (2006, p. 38), “[...] a análise do campo investigativo é fundamental neste tempo de intensas mudanças associadas aos avanços crescentes da ciência e tecnologia".

Fatinato e Freitas (2018) e Teixeira (2006), colocam que pesquisas do tipo "estado da arte" se tornam promissoras por permitir mapear, discutir e atualizar determinada produção acadêmica em múltiplos campos do conhecimento, promovendo um caráter permanente dos bancos de dados. As autoras reafirmam isso ao citar o trabalho de Ferreira (2002), que diz que nesse mapeamento busca-se respostas para aspectos e dimensões que estão em destaque ao longo do tempo e em diferentes espaços, possibilitando ainda refletir sobre como têm sido produzidos trabalhos de pesquisas em múltiplos níveis acadêmicos, como é o caso de estudos que abrangem dissertações/teses de mestrados/doutorados e/ou trabalhos publicados em periódicos, eventos, congressos e seminários da área. Além disso, Ferreira, ao citar o trabalho de Soares, nos coloca que:

Essa compreensão do estado de conhecimento sobre um tema, em determinado momento, é necessária no processo de evolução da ciência, afim de que se ordene periodicamente o conjunto de informações e resultados já obtidos, ordenação que permita indicação das possibilidades de integração de diferentes perspectivas, aparentemente autônomas, a identificação de duplicações ou contradições, e a determinação de lacunas e vieses (Soares, 1987 apud Ferreira, 2002, p. 259).

Pesquisando no âmbito da educação em Ciências, Teixeira e Megid Neto (2012, p. 275) apontam algo similar ao dizerem que o "estado da arte" é: 
[...] a investigação analisa, num recorte temporal definido, as características da evolução histórica e os movimentos de um determinado campo de pesquisa, revelando continuidades e mudanças de rumo, as tendências temáticas e metodológicas, os principais resultados das investigações, as lacunas e áreas não exploradas, detectando vazios e silêncios da produção, e, indicando novos caminhos de pesquisa, dentre muitos outros aspectos.

Pautados nas considerações teóricas expostas, consideramos como promissor um estudo do tipo "estado da arte" sobre a "avaliação da aprendizagem”, dado que, tal como aponta por Borges (2011), a produção de pesquisas sobre “avaliação", em periódicos reconhecidos pela área de $E_{n} \operatorname{sino}^{2}$ (área 46), apresenta-se em vias de consolidação, caracterizando-se como algo essencial no processo de construção desse conhecimento. Nessa perspectiva, nossa pesquisa se justifica por ter potencial de ser objeto de estudo de pesquisadores que buscam sistematizar/analisar o material referente ao tema.

\section{Desenvolvimento da Pesquisa}

O mapeamento da produção científica sobre o tema "avaliação da aprendizagem", se deu a partir da análise de um importante periódico da área de pesquisa em Educação em Ciências, considerando aqui os aportes teórico-conceituais desses estudos. Considerando que este estudo se trata de um recorte de uma pesquisa de maior amplitude, mapeamos as publicações sobre o tema na revista "Ciência \& Educação" no período de 1998 a 2017.

O periódico em questão foi criado em 1995, no âmbito do Programa de Pós-Graduação em Educação para a Ciência da Faculdade de Ciências da Universidade Estadual Paulista “Júlio de Mesquita Filho” (UNESP/Bauru-SP). Ele tem como objetivo publicar trabalhos científicos originais de educação em ciências, educação matemática e áreas afins, apresentando periodicidade com edições nos meses de março, junho, setembro e dezembro ${ }^{3}$.

A escolha por analisar as publicações deste periódico se pauta no fato de que ele se constitui como um espaço de publicação de pesquisas de excelência, visto que é classificado no estrato Qualis ${ }^{4}$ A1 na Área de Ensino (quadriênio 20132016). Assim, consideramos que, possivelmente, pesquisadores influentes da área publicam seus trabalhos neste periódico e, consequentemente, isso poderá nos levar a identificação de alguns estudos importantes que vêm sendo produzidos no âmbito das pesquisas em educação em Ciências. Visando uma significativa abrangência das buscas, as fontes de informação deste estudo, que se enquadra na modalidade "documentos", trata-se de artigos científicos publicados no periódico durante o período de quase duas décadas (1998-2017).

De modo a compreender os principais enfoques, tendências e concepções das pesquisas em Ensino de Ciências sobre o tema "avaliação da aprendizagem" dentro do recorte temporal definido (Teixeira \& Megid Neto, 2012), o que caracteriza o "estado da arte", inicialmente selecionamos artigos que apresentavam em seus títulos ao menos um dos termos busca de busca por nós definido (“avaliação", “avaliação da aprendizagem”, “evaluation”, "learning evaluation”). Esse critério justificou-se pelo fato de o foco/tema da pesquisa relacionar-se com o assunto "avaliação da aprendizagem".

\footnotetext{
${ }^{2}$ A Área de Ensino (Área 46) está inserida na grande Área Multidisciplinar, a partir da constituição e decisão do Conselho Superior da CAPES pela Portaria CAPES n 83 de 6 de junho de 2011. Dessa decisão foram criadas quatro áreas: Ensino, Ciências Ambientais, Biodiversidade e Nutrição. Desse modo, a "Área de Ensino caracteriza-se como uma área especialmente de pesquisa translacional, a partir da relação entre conhecimentos acadêmicos, gerados em Educação e Ensino para seu desenvolvimento em produtos e processos educativos para com a sociedade" (Capes, 2013, p. 1).

${ }^{3}$ Ao longo de sua história, a revista "Ciência \& Educação" teve alterações quanto ao número anual de edições publicadas. Desde 2020, as publicações são feitas em fluxo contínuo. Porém, quando fizemos o levantamento bibliográfico deste estudo (início de 2018), o periódico apresentava periodicidade quadrimestral. Disponível em: https://www.fc.unesp.br/\#!/ensino/pos-graduacao/programas/educacao-para-aciencia/revista-ciencia-e-educacao/sobre-a-revista/historico/. Acesso em: 31 maio 2021.

${ }^{4} \mathrm{O}$ Qualis-Periódicos é um sistema de classificação da produção científica. O Qualis classifica os periódicos e outros tipos de produção. No quadriênio 2013-2016, utilizado nesta pesquisa, a classificação é realizada por áreas de avaliação e passa por processo anual de atualização. Destarte, os periódicos são enquadrados em estratos indicativos de qualidade, apresentados em ordem decrescente: A1; A2; B1; B2; B3; B4; B5; C. Disponível em: <https://sucupira.capes.gov.br/sucupira/public/index.jsf>. Acesso em: 19 nov. 2018.
} 
Destarte, após a leitura dos títulos, resumos e palavras-chave de todas as pesquisas, em um universo de 768 publicações encontradas, selecionamos para fins de categorização 9 artigos que apresentavam foco explícito no tema "avaliação da aprendizagem". Após mapear e a organizar as informações obtidas por meio das buscas, caracterizamos a pesquisa a partir da delimitação dos seguintes descritores: a) Título; b) Autores; c) Ano de publicação; d) aportes teóricosconceituais, que, grosso modo, são extratos dos textos originais que trazem resumidamente as concepções de avaliação assumida pelos autores; e) categorização do tipo de concepção assumida nos estudos.

\section{Procedimento Analítico e Discussão dos Resultados}

A seguir apresentamos uma síntese dos resultados obtidos por meio de quadros. No Quadro 1 apresentamos os 9 artigos selecionados, a partir de seus títulos e fazendo referência aos seus autores e ano de publicação. Para análise dos artigos selecionados utilizamos o instrumento de coleta de informações denominado Roteiro De Análise Textual (RAT) ${ }^{5}$, tendo como principal critério de análise a compreensão dos "aportes teórico-conceituais", conforme apresentamos no Quadro 2.

De acordo com Miguel e Terrazzan (2019, p. 6), o RAT permite a construção de uma análise que colabora "na compressão do critério investigado de cada pesquisa, objetivando interpretar e analisar com o maior aprofundamento possível". Neste estudo, optamos por categorizar as principais concepções de avaliação assumidas pelos textos que compõem o corpus de análise a partir de fragmentos significativos, os quais denominamos "fragmentos-síntese". A partir deles, estabelecemos um movimento descritivo-interpretativo e classificatório a respeito dos resultados encontrados.

Quadro 1. Identificação dos artigos selecionados para análise.

\begin{tabular}{|l|l|}
\hline ID & \multicolumn{1}{|c|}{ Identificação dos Artigos } \\
\hline Art01 & $\begin{array}{l}\text { Buscando um sistema de avaliação contínua: ensino de eletrodinâmica no nível médio (Filho \& } \\
\text { Silva, 2002) }\end{array}$ \\
\hline Art02 & $\begin{array}{l}\text { Professores - pesquisadores: reflexão e mudança metodológica no ensino de física - o contexto da } \\
\text { avaliação (Rodrigo \& Carvalho, 2002) }\end{array}$ \\
\hline Art03 & $\begin{array}{l}\text { Avaliação formativa: a auto-avaliação do aluno e a autoformação de professores (Carvalho \& } \\
\text { Martinez, 2005) }\end{array}$ \\
\hline Art04 & $\begin{array}{l}\text { Desenvolvimento de habilidades no ensino de ciências e o processo de avaliação: análise da } \\
\text { coerência (Maia \& Justi, 2008) }\end{array}$ \\
\hline Art05 & $\begin{array}{l}\text { Práticas de avaliação de professores de ciências físico-químicas do ensino básico (Correia \& } \\
\text { Freire, 2010) }\end{array}$ \\
\hline Art06 & $\begin{array}{l}\text { Concepções de um professor de física sobre avaliação: um estudo de caso (Lima, Tenório, \& } \\
\text { Bastos, 2010) }\end{array}$ \\
\hline Art07 & $\begin{array}{l}\text { Avaliação em matemática: uma leitura de concepções e análise do vivido na sala de aula (Paulo \& } \\
\text { Santos, 2011) }\end{array}$ \\
\hline Art08 & $\begin{array}{l}\text { A Taxionomia revisada de Bloom aplicada à avaliação: um estudo de provas escritas de } \\
\text { Matemática (Trevisan \& Amaral, 2016) }\end{array}$ \\
\hline Art09 & $\begin{array}{l}\text { Atividades experimentais no ensino da química: distanciamentos e aproximações da avaliação de } \\
\text { quarta geração (Andrade \& Viana, 2017) }\end{array}$ \\
\hline
\end{tabular}

Fonte: Dados da pesquisa (2018).

${ }^{5}$ O RAT utilizado para analisar os artigos selecionados é de autoria do professor pesquisador Eduardo Adolfo Terrazzan, em conjunto com o Grupo de Pesquisa INOVAEDUC, estabelecido como instrumento de coleta de informações para diversos tipos de documentos (artigos PAC, dissertações de mestrado, teses de doutorado). O RAT procura sistematizar as informações presentes nos documentos analisados. 
Quadro 2. Roteiro de Análise Textual para pesquisa empírica.

\begin{tabular}{|c|c|c|c|c|c|}
\hline \multicolumn{6}{|c|}{$\begin{array}{l}\text { Roteiro De Análise Textual } \\
\text { (Pesquisa Empírica) }\end{array}$} \\
\hline ID & Título & Autores & Ano & Aporte Teórico- Conceitual & Categoria \\
\hline-- & -- & --- & -- & -- & -- \\
\hline
\end{tabular}

Fonte: Dados da pesquisa (2018).

A fim de caracterizar as pesquisas encontradas a partir do critério de análise, realizamos uma minuciosa leitura dos 9 artigos que constituíram a amostra final dos dados. Para o tratamento dos dados, estabelecemos categorias que objetivaram interpretar e analisar os textos de acordo com o critério definido, conforme apresentamos no Quadro 3. Destarte, na primeira coluna do Quadro 3 apresentamos a nomenclatura de identificação dos artigos, numerando-os de 1 a 9. Na coluna seguinte colocamos o ano de publicação. Em seguida, apresentamos os extratos originais, que se referem aos aportes teórico-conceituais adotados por cada artigo a partir de "fragmentos-síntese". Por fim, na última coluna, descrevemos a categoria estabelecida para cada aporte.

Quadro 3. Categorias estabelecidas a partir dos aportes teórico-conceituais presente nos artigos analisados.

\begin{tabular}{|c|c|c|c|}
\hline ID & Ano & $\begin{array}{c}\text { Aportes teórico-conceituais } \\
\text { (extratos originais para análise) }\end{array}$ & Categoria \\
\hline & \multirow[t]{2}{*}{2002} & $\begin{array}{l}\text { Ela é um dos determinantes, constituindo-se muitas vezes o "coração" de todo } \\
\text { o processo de ensino e aprendizagem (Alonso, 1995; Carvalho et al., 1995; } \\
\text { Aedo, 1996; Gonzáles, 1996; Michel, 1996; Silva e Barros Filho, 1997). }\end{array}$ & $\begin{array}{l}\text { Integrante da prática } \\
\text { educativa }\end{array}$ \\
\hline Art1 & & $\begin{array}{l}\text { Por outro lado, a avaliação é um requisito básico para o melhoramento da } \\
\text { qualidade de ensino, à medida que pode vir a ser usada como um instrumento } \\
\text { de feedback tanto para os professores quanto para os alunos (Alonso et al., } \\
\text { 1992-b; Alonso, 1995; Peláez, 1995; Rivilla et al., 1995; Aedo, 1996; } \\
\text { Giménez et al., 1996; González, 1996; Lobo, 1996; Toranzos, 1996; Silva e } \\
\text { Barros Filho, 1997). }\end{array}$ & $\begin{array}{l}\text { Melhora a qualidade de } \\
\text { ensino }\end{array}$ \\
\hline Art2 & 2002 & $\begin{array}{l}\text { Segundo Alonso (apud Gil-Pérez, 1991), a avaliação é uma atividade que } \\
\text { desempenha um papel importante porque evidencia os aspectos de } \\
\text { insuficiência do ensino e aprendizagem. Sendo então um campo privilegiado } \\
\text { para incidir na transformação do ensino e, em particular, para propiciar } \\
\text { situações de reflexão sobre idéias e comportamentos espontâneos, que atuam } \\
\text { como autênticos obstáculos à renovação (Gil-Pérez et al., 1991). }\end{array}$ & $\begin{array}{l}\text { Integrante da prática } \\
\text { educativa }\end{array}$ \\
\hline Art03 & 2005 & $\begin{array}{l}\text { Enquanto a verificação dos conhecimentos adquiridos ao final de um período } \\
\text { (avaliação somativa) implica na consideração do erro como uma "falta" } \\
\text { definitiva de algo (uma vez que não se pretende voltar mais a ele), no enfoque } \\
\text { da avaliação formativa, essa falta é apenas momentânea. A falta apontada pelo } \\
\text { erro é, então, considerada como parte integrante do processo de } \\
\text { aprendizagem. Assim, o processo da avaliação formativa consiste em } \\
\text { caminhar por sucessivas aproximações e por constantes redefinições de metas. } \\
\text { [...] A avaliação formativa implica a crença de que pequenas mudanças podem } \\
\text { e devem ser, incansavelmente, implementadas na prática de ensino. }\end{array}$ & $\begin{array}{l}\text { Atividade formativa, } \\
\text { de maneira que as } \\
\text { ações que envolvem o } \\
\text { processo de } \\
\text { aprendizagem estão em } \\
\text { constantes mudanças e } \\
\text { redefinição de metas }\end{array}$ \\
\hline
\end{tabular}




\begin{tabular}{|c|c|c|c|}
\hline Art04 & 2008 & $\begin{array}{l}\text { As avaliações de massa, assim como qualquer outra avaliação escrita, são } \\
\text { instrumentos que devem conter questões que permitam aos estudantes } \\
\text { explicitar suas idéias, envolvendo contextos nos quais eles possam transferir } \\
\text { um conhecimento e/ou habilidade para novas situações- problema. Isto torna } \\
\text { válido o uso de questões abertas - envolvendo problemas nos quais os } \\
\text { estudantes deverão aplicar e explicitar o conhecimento que está sendo } \\
\text { requerido. Tais questões devem ser contextualizadas - cobrando um } \\
\text { conhecimento estratégico, e não apenas declarativo - e apresentar exigências } \\
\text { coerentes com o que se deseja avaliar. }\end{array}$ & $\begin{array}{l}\text { Instrumentos que } \\
\text { permitem aos } \\
\text { estudantes explicitar } \\
\text { suas ideias/transferir } \\
\text { conhecimento e/ou } \\
\text { habilidades para novas } \\
\text { situações problemas }\end{array}$ \\
\hline Art05 & 2010 & $\begin{array}{l}\text { Avaliar é importante, mas como meio privilegiado para se compreender } \\
\text { melhor a situação de modo a intervir de forma fundamentada. [...] Esta ideia } \\
\text { de que a avaliação deve ser parte integrante do processo de ensino- } \\
\text { aprendizagem, com o objectivo de melhorar as aprendizagens [...]. Mas estas } \\
\text { novas ideias fazem importantes exigências aos professores, implicando } \\
\text { mudanças a nível das suas concepções e das suas práticas (BORKO et al., } \\
\text { 1997). Para mudar a avaliação, segundo Earl (2003), é necessário que o } \\
\text { professor compreenda que a avaliação e a aprendizagem estão inter- } \\
\text { relacionadas. }\end{array}$ & $\begin{array}{l}\text { Integrante da prática } \\
\text { educativa }\end{array}$ \\
\hline Art6 & 2010 & $\begin{array}{l}\text { Além disso, Silva (2004) afirma que a avaliação é concebida como } \\
\text { constituinte da ação educativa, como algo que entra no processo de diálogo } \\
\text { entre o planejamento, o ensino e a aprendizagem, e não um mecanismo que se } \\
\text { propõe a medir, de fora, os resultados desse processo. [...] Dessa maneira, } \\
\text { vislumbra-se uma perspectiva emergente de avaliação, na qual ela é } \\
\text { promotora da formação e, como tal, mediadora e integrante do processo de } \\
\text { ensino-aprendizagem, contribuindo fundamentalmente para a contínua revisão } \\
\text { do processo (LIMA, TENÓRIO e BASTOS). }\end{array}$ & $\begin{array}{l}\text { Integrante da prática } \\
\text { educativa }\end{array}$ \\
\hline \multirow[t]{2}{*}{ Art7 } & \multirow[t]{2}{*}{2011} & $\begin{array}{l}\text { Dos autores visitados, optamos por trazer para a discussão, neste artigo, } \\
\text { Luckesi (1995), para quem a avaliação pode ser entendida como "um juízo de } \\
\text { qualidade sobre dados relevantes, tendo em vista uma tomada de decisão" } \\
\text { (LUCKESI, 1995, p. 69, grifos nossos). }\end{array}$ & $\begin{array}{l}\text { Atividade que } \\
\text { qualifica/emite juízo } \\
\text { de dados relevantes }\end{array}$ \\
\hline & & $\begin{array}{l}\text { Para Hoffmann (1998), a avaliação envolve uma relação com o processo de } \\
\text { conhecimento do aluno e os modos pelos quais esse conhecimento é } \\
\text { adquirido. }\end{array}$ & $\begin{array}{l}\text { Integrante da prática } \\
\text { educativa }\end{array}$ \\
\hline Art08 & 2016 & $\begin{array}{l}\text { Fundamentalmente, avaliar é emitir juízo de valor, após análises e ou sínteses } \\
\text { efetuadas. É uma apreciação qualitativa sobre dados relevantes dos processos } \\
\text { de ensino e aprendizagem que auxilia o professor a tomar decisões sobre o seu } \\
\text { trabalho (MORETTO, 2010). [...] A avaliação é um julgamento de valor sobre } \\
\text { manifestações relevantes da realidade, tenso em vista uma tomada de decisão. } \\
\text { [...] Nessa concepção, não há avaliação se ela não trouxer um diagnóstico que } \\
\text { contribua para melhorar a aprendizagem. }\end{array}$ & $\begin{array}{l}\text { Atividade que } \\
\text { qualifica/emite juízo } \\
\text { de dados relevantes }\end{array}$ \\
\hline Art9 & 2017 & Não foram encontrados explícitos aportes teórico-conceituais nesse artigo. & --- \\
\hline
\end{tabular}

Fonte: Dados da pesquisa (2018). 
Como mostra o Quadro 3, a partir dos 9 artigos selecionados, estabelecemos 10 categorias que acreditamos que podem ajudar na compreensão dos "aportes teórico-conceituais" adotados pelas pesquisas. Entre todos os artigos, apenas o de número 9 (“Art9”) não apresentou nenhum aporte.

No "Art1" foram identificadas duas categorias: 1) "Integrante no processo de ensino e aprendizagem"; e 2) "Melhora a qualidade de ensino". Dessa forma, pela primeira categoria percebe-se que o conceito atribuído à avaliação está intimamente relacionado com o processo de ensino e aprendizagem, enquanto a segunda categoria trata a avaliação como uma ação que pode "melhorar" algo, ou seja, nessa perspectiva a avaliação é integrante da prática educativa e pode ser considerada como uma atividade relevante para a elevação da qualidade do ensino. Nessa perspectiva:

[...] podemos partir do pressuposto de que a avaliação, como prática escolar, não é uma atividade neutra ou meramente técnica, isto é, não se dá em um vazio conceitual, mas é dimensionada por um modelo teórico de mundo, de ciência e de educação, traduzida em prática pedagógica (Chueiri, 2008, p. 52).

Nos Art2, Art5, Art6 e Art7 identificamos a categoria "Integrante da prática educativa", sendo que para o "Art7" foi definida mais de uma categoria. Nesse sentido, compreendemos que nessas pesquisas a avaliação - percebida como integrante dos processos que envolvem o ensino e a aprendizagem, tanto do professor quanto dos alunos - tem um caráter formativo. Em outras palavras, podemos dizer que, quando se trata de uma forma de avaliação que considera diferentes momentos/instrumentos, esses instrumentos tornam-se flexíveis para com os processos de aprendizagem. Nesse contexto, como mencionamos, Muramoto (1991) aponta que a avaliação deve ir além da sala de aula. Nessa perspectiva compreende-se como necessária a reflexão sobre o julgamento que realizamos durante o processo avaliativo, de modo a entendermos as atividades (e as relações) desenvolvidas na escola, relacionando-as com reflexões sobre o trabalho pedagógico.

Referente ao "Art3", definimos a categoria "Atividade formativa". Essa categoria pauta-se no pressuposto de que as ações que envolvem o processo de aprendizagem estão em constante mudança e redefinição de metas. Evidencia-se, portanto, a ideia de avaliação formativa enquanto prática educativa, quando ela envolve a flexibilidade nas ações, tanto de realização quanto de definição de objetivos/metas para a aprendizagem. Nessa perspectiva, uma das principais funções da avaliação caracteriza-se por "contribuir para uma boa regulação da atividade de ensino" (ou da formação, no sentido amplo) (Hadji, 2001, p. 19).

A partir da análise do "Art4" estabelecemos a categoria "instrumentos que permitem aos estudantes explicitar suas ideias/transferir conhecimento e/ou habilidades para novas situações problemas". A partir dela, considera-se que a avaliação, quando leva em conta a regulação da aprendizagem e o feedback dos envolvidos no processo, em geral, torna-se mais eficaz e, portanto, qualifica a obtenção das metas definidas. Essa perspectiva considera a realidade dos sujeitos envolvidos na ação pedagógica (André \& Passos, 2001). Em outras palavras, este aporte teórico-conceitual aponta para a necessidade de considerar que cada grupo é formado por indivíduos com histórias pessoais, sociais, familiares, culturais, educacionais bem variadas, e que, para envolver esses indivíduos, se faz necessário o desenvolvimento de atividades e instrumentos diferenciados.

Para o "Art7", estabelecemos duas categorias: 1) "Atividade que qualifica/emite juízo de dados relevantes"; e 2) "Integrante da prática educativa". A primeira categoria também se relaciona ao "Art8". Nos dois (Art7 e Art8), não são apresentadas informações a respeito do que seriam os "dados relevantes" a serem julgados neste processo, porém, com base em outras leituras apresentadas pelo autor, evidencia-se que esses dados podem ser caracterizados, de modo geral, por meio de ações educativas. Outrossim, a segunda categoria relaciona-se com as de outros artigos categorizados, uma vez que traz o conceito de avaliação baseado na ideia de integração dos processos de ensino e de aprendizagem. Isso vai ao encontro do que aponta Hoffman, ao dizer que a avaliação é: 
[...] uma ação ampla que abrange o cotidiano do fazer pedagógico e cuja energia faz pulsar o planejamento, a proposta pedagógica e a relação entre todos os elementos da ação educativa. Basta pensar que avaliar é agir com base na compreensão do outro, para se entender que ela nutre de forma vigorosa todo o trabalho educativo (Hoffmann, 2008, p. 17).

Nesse viés, entendemos que a "qualificação" / "emissão de juízo" sobre qualquer prática avaliativa, dentro do contexto educativo, não deve se restringir apenas ao professor, mas abranger toda a escola, os alunos (e seus responsáveis) e a gestão escolar. Destarte, o objetivo principal nessa perspectiva avaliativa é que todos possam conscientizar-se da importância de sua função na prática educativa, além de apontar para a necessidade de desenvolverem-se diferentes momentos avaliativos, cabendo, a partir disso, a tomada de consciência quanto aos instrumentos utilizados e em relação às possibilidades de construção de conhecimentos pelos alunos.

De acordo com este movimento descritivo-interpretativo (e reflexivo), observamos que, a partir dos artigos selecionados, foi possível estabelecer diferentes categorias. Essas categorias emergiram a partir de aportes teórico-conceituais identificados nos textos que encontramos nas buscas bibliográficas. Neste interim, sinteticamente, podemos dizer que as categorias estabelecidas apontam a avaliação como: a) Determinante no processo de ensino e aprendizagem; b) Possibilidade de melhora na qualidade de ensino; e c) Constituinte fundamental do processo de ensino e de aprendizagem. Destarte, em suma, os artigos analisados apresentaram uma multiplicidade de conceitos relacionados ao tema "avaliação da aprendizagem" no Ensino de Ciências.

\section{Considerações Finais}

Compreendendo que o nosso objetivo se pautou em mapear a produção científica sobre "avaliação da aprendizagem", considerando os seus aportes teórico-conceituais e dentro critérios analíticos específicos, algumas reflexões se fazem frutíferas a respeito dos dados encontrados.

Por meio de uma análise criteriosa, dentro do período estabelecido, encontramos apenas 9 artigos com o foco no tema "Avaliação da Aprendizagem" no periódico "Ciência \& Educação" (Qualis A1/Ensino/CAPES/Brasil). Nesse sentido, observamos que, em média, as publicações sobre este tema no periódico de interesse ocorreram a cada dois anos. Considerando que este é um dos principais periódicos da área, este resultado nos parece indicar um baixo índice de estudos sobre o tema.

A partir da categorização por nós estabelecida e que se deu por meio da análise dos aportes-teóricos conceituais dessas pesquisas, observamos que os artigos apresentam distintas concepções a respeito do conceito de "avaliação". Além disso, a maioria dos estudos relaciona o conceito de avaliação da aprendizagem a uma ação "integrante da prática educativa". Com base nos resultados obtidos, consideramos que as questões que concernem à avaliação da aprendizagem, enquanto um instrumento crucial e necessário no âmbito escolar, tem sido apontado como algo necessário a ser (re)pensado na Educação em Ciências. Esse repensar, que ser quer crítico, vê a avaliação como algo que é mais do que um instrumento finalista, que "mede" conhecimentos. Nessa percepção outra de compreensão da eficácia do processo de ensino-aprendizagem, a avaliação é vista numa ótica construtiva, em seus múltiplos aspectos. Isso quer dizer que a avaliação não apenas afere os conhecimentos, como é parte integrante de sua construção, podendo, a partir dela, delimitar outras possibilidades e percursos de ensino e de aprendizagem.

Acreditamos que estudos como este, do tipo "estado da arte", podem não só trazer parâmetros sobre a produção acadêmica, como também apontar para outras percepções sobre (e formas de olhar para) a avaliação. Nesse viés, a partir das reflexões expostas, esperamos que outras pesquisas, teóricas, analíticas e/ou empíricas, possam refletir sobre a avaliação da aprendizagem na educação científica e tecnológica. Ademais, apontamos para a importância de que essas escritas não apenas ocupem espaços científicos, mas que também venham a abranger instâncias de outras ordens, pois compreendemos que o ato 
de avaliar, ainda que perpassado por questões de complexo entendimento, configura-se como uma das práticas mais usuais e importantes em diferentes âmbitos educacionais.

Por fim, assumimos que um estudo que se pauta na análise de um único periódico possui limitações. Nesse sentido, a nível de pesquisas futuras podemos dizer que, em sua tese de doutorado, a primeira autora deste estudo tem se debruçado em analisar demais periódicos do Brasil e de Portugal a respeito do tema "Avaliação da Aprendizagem", numa pesquisa comparativa que busca compreender como a temática tem sido retratada no âmbito da Educação, em particular no que se refere à Educação em Ciências e com especial foco no Ensino Superior. Dada a relevância dessas questões, acreditamos que outros estudos, teóricos e/ou empíricos, em diferentes níveis e contextos de ensino, se fazem necessários a respeito do tema.

\section{Agradecimentos}

Esta pesquisa foi realizada com apoio da Coordenação de Aperfeiçoamento de Pessoal de Nível Superior (CAPES) e do Conselho Nacional de Desenvolvimento Científico e Tecnológico (CNPq).

\section{Referências}

André, M. E. D. A., \& Passos, L. F. (2001). Avaliação escolar: desafios e perspectivas. In: Castro, A. D., \& Carvalho, A. M. P. (org.) Ensinar a ensinar: didática para a escola fundamental e média. Thomson Learning, 177-195.

Barreira, C., Boavida, J., \& Araújo, N. (2006). Avaliação formativa. Novas formas de ensinar e aprender. Revista Portuguesa de Pedagogia, $40(3)$, 95-133.

Borges, R. M. (2011). Avaliação na educação básica, o estado do conhecimento na revista Ensaio: avaliação e políticas públicas em educação (1999-2008) (Dissertação de Mestrado), Pontifícia Universidade Católica de Campinas

Capes. (2013). Coordenação de Aperfeiçoamento de Pessoal de Nível Superior. Documento de Área, 36.

Chueiri, M. S. F. (2008). Concepções sobre avaliação escolar. Estudos em Avaliação Educacional, 19(39), 49-64.

Depresbiteris, L. (1997). Avaliação da aprendizagem: Revendo conceitos e posições. In: C. P. Sousa (Org.). Avaliação do rendimento escolar. 6. ed., Campinas: Papirus, p. 51-79.

Fantinato, M. C., \& Freitas, A. V. (2018). Etnomatemática: concepções, dinâmicas e desafios. Paco Editorial.

Fernandes, D. (2009). Avaliar para aprender: fundamentos, práticas e políticas. Editora Unesp:

Ferreira, N. S. A. (2002). As pesquisas denominadas “estado da arte”. Educação e Sociedade, 23(79).

Fiorentini, D. \&Lorenzato, S. (2006). Investigação em Educação Matemática: percursos teóricos e metodológicos. Campinas: Autores Associados.

Flick, U. (2009). Qualidade na pesquisa qualitativa. Artmed.

Gil, A. C. (2008). Métodos e técnicas de pesquisa social. (6a ed.), Atlas.

Hadji, C. (2001). Avaliação desmistificada. Artmed.

Hoffmann, J. M. L. (1995). Avaliação mito e desafio: uma perspectiva construtivista. (24a ed.), Mediação.

Hoffmann, J. M. L. (2008). Avaliar para promover: as setas do caminho. Mediação.

Liell, C. C., Bayer, A., \& Ledur, J. R. (2018). Concepções dos Professores e Gestores sobre as Avaliações Externas da Região da $2^{\text {a }}$ Coordenadoria de Educação do Estado do Rio Grande do Sul. Acta Scientiae, Canoas, 20(3), 506-518.

Luckesi, C. C. (1996). Avaliação da aprendizagem escolar: estudos e proposições. (3a ed.), Cortez.

Lüdke, M., \& André, M. E. D. A. (1986). Pesquisa em educação: abordagens qualitativasEPU.

Machado, A. C., Fernandes, C, D. M., Pereira, A. M. P., Souza, É. S., Rufino, M. V. M., \& Oliveira, E. N. S. (2021). Avaliação da aprendizagem no Ensino Superior. Research, Society and Development, 10(6), 1-13.

Miguel, K. S., \& Terrazzan, E. A. (2019). Caracterização de pesquisas acadêmico- científicas sobre práticas docentes da educação básica, publicadas em periódicos nacionais entre 2006 e 2018. Revista Atlante: Cuadernos de Educación y Desarrollo.

Minayo, M. C. S., Deslandes, S. F., Cruz Neto, O., \& Gomes, R. (1994). Pesquisa social: teoria, método e criatividade. Vozes. 
Research, Society and Development, v. 10, n. 8, e8110817104, 2021

(CC BY 4.0) | ISSN 2525-3409 | DOI: http://dx.doi.org/10.33448/rsd-v10i8.17104

Montalvão Neto, A. L., \& Miguel, K. S. (2019). Práticas cotidianas escolares: reflexões a partir da visão de licenciandos sobre "ser professor" mediante experiências no Estágio Supervisionado em Ciências. In: Silveira, É. L.; Santana, W. K. F. (Orgs.). Educação: ressonâncias teóricas e práticas. Volume 2. : Pedro \& João Editores, 341p.

Muramoto. H. M. S. (1991). Supervisão da escola, para que te quero? Uma proposta aos profissionais da educação na escola pública. São Paulo: Iglu.

Patton, M. Q. (2001). Qualitative research and evaluation methods. Sage Publications.

Perrenoud, P. (1999). Avaliação: da excelência à regulação das aprendizagens - entre duas lógicas. Artes Médicas Sul.

Pinto, R. O., \& Rocha, M. S. P. M. L. (2011). A avaliação formativa: reflexões sobre o conceito no período de 1999 a 2009 . Estudos em Avaliação Educacional, São Paulo, 22(50), 553-576.

Reis, A, C. E., Wendling, C. M., Miguel, K. S., Peron, L. D. C., Bar, M. V., Santos, S. C. S., Meier, W. M. B., \& Cunha, M. B. (2020). Análise dos Periódicos Qualis/CAPES. HIPÁTIA - Revista Brasileira de História, Educação e Matemática, 5(1), 11-24.

Romanowki, J. P., \& Ens, R. T. (2006). As pesquisas denominadas do tipo “estado da arte” em educação. Diálogo educacional, Curitiba, 6(19), 37-50.

Sanmartí, N. (2009). Avaliar para aprenderArtmed Editora.

Saul, A. M. (1994). Avaliação emancipatória. (2a ed.), Cortez.

Scriven, M. (1967). Perspectives of curriculum evaluation. Washington, D. C: American Educational Research Association.

Scriven, M. (2007). The logic of evaluation: department of Psychology. Claremont Graduate University.

Teixeira, C. R. O. (2006). "Estado da Arte": a concepção de avaliação educacional veiculada na produção acadêmica do Programa de Pós-Graduação em Educação: Currículo (1975-2000). Cadernos de Pós-Graduação - Educação, 5(1), 59-66.

Teixeira, P. M. M., \& Megid Neto, J. (2012). O estado da arte da pesquisa em ensino de Biologia no Brasil: um panorama baseado na análise de dissertações e teses. Revista Electrónica de Enseñanza de las Ciencias, Vigo, 11(2), 273-297.

Vianna, H. M. (1989). A prática da avaliação educacional: algumas colocações metodológicas. Cadernos de pesquisa, 69, 40-47. 